\title{
Comportamento Ingestivo de Novilhas Leiteiras Alimentadas com Dietas à Base de Cana-de-açúcar ${ }^{1}$
}

\section{Lídia Ferreira Miranda ${ }^{2}$, Augusto César de Queiroz ${ }^{3}$, Sebastião Campos Valadares Filho ${ }^{3}$, Paulo Roberto Cecon ${ }^{4}$, Elzânia Sales Pereira ${ }^{5}$, José Maurício de Souza Campos ${ }^{3}$, Rogério de Paula Lanna $^{3}$, José Rafael Miranda ${ }^{6}$}

\begin{abstract}
RESUMO - O objetivo deste trabalho foi avaliar o comportamento ingestivo de novilhas mestiças Holandês x Zebu alimentadas com dietas à base de cana-de-açúcar suplementadas com fontes de nitrogênio não-protéico [NNP] (uréia e cama de frango, em substituição parcial da uréia) e, ou, adição de probióticos (sem probiótico, com levedura ou com microbiota ruminal). Vinte e quatro novilhas, com idade e peso médio inicial de 15 meses e $247 \mathrm{~kg}$, respectivamente, foram mantidas em baias individuais e alimentadas à vontade, durante o período experimental de 84 dias. Os animais foram distribuídos em delineamento inteiramente casualisado, em esquema fatorial 2 x 3 (fontes de NNP vs fontes de probiótico), com quatro repetições. O comportamento ingestivo de cada novilha foi determinado visualmente, a cada 28 dias, a intervalos de 10 minutos, durante 24 horas. Não houve diferença no tempo despendido em alimentação, ruminação e mastigação total, em min/dia, das novilhas alimentadas com diferentes fontes de NNP e probióticos. O tempo médio de ruminação, em $\mathrm{min} / \mathrm{kg}$ de MS e FDN, foi maior para os animais alimentados com uréia. O comportamento ingestivo das novilhas não foi influenciado pelas fontes de nitrogênio ou pela adição de probiótico.
\end{abstract}

Palavras-chave: cana-de-açúcar, comportamento ingestivo, novilhas, probiótico

\section{Ingestive Behavior of Dairy Heifers Fed Sugar Cane Based Diets}

\begin{abstract}
The objective of this work was to evaluate the ingestive behavior of crossbred dairy heifers fed sugar-cane based diets, supplemented with non protein nitrogen [NPN] sources (urea or broiler litter, in replacement of urea) and, or, probiotics addition (without probiotic, with yeast or with ruminal microbiota). Twenty-four heifers, with age and average initial weight of 15 months and $247 \mathrm{~kg}$, respectively, were maintained in individual stalls and ad libitum fed during the experimental period of 84 days. The animals were allotted to a completely randomized design, in a 2 x 3 factorial arrangement (NPN source vs probiotic source), with four replicates. The ingestive behavior of each heifer was visually determined, at 28 days, in intervals of 10 minutes, during 24 hours. There was no difference on the time spent in feeding, rumination and total chewing, in min/day, of the heifers fed different sources of NPN and probiotics. The average rumination time in $\mathrm{min} / \mathrm{kg}$ of DM and NDF were higher for the animals fed urea. The ingestive behavior of the heifers was not affected by the nitrogen sources or by the probiotic addition.
\end{abstract}

Key words: sugar cane, ingestive behavior, heifers, probiotic

\section{Introdução}

Para entendimento completo do consumo diário de alimentos, é necessário estudar seus componentes individualmente, que podem ser descritos pelo número de refeições consumidas por dia, pela duração média das refeições e pela velocidade de alimentação de cada refeição. Cada um desses processos é o resultado da interação entre o metabolismo do animal e das propriedades físicas e químicas da dieta, estimulando receptores da saciedade. No sentido de aumentar o consumo diário, é necessário aumentar uma ou mais dessas três variáveis descritas anteriormente, entretanto, a velocidade de alimentação de cada refeição está mais relacionada com o consumo de matéria seca do que com o número de refeições diárias. Dessa forma, mensurar o comportamento de alimentação e a ruminação diária animal pode proporcionar mecanismo de auxílio para análise destes componentes que contribuem para o consumo diário (DADO e ALLEN, 1994; THIAGO et al., 1992).

A forma física da dieta influencia o tempo

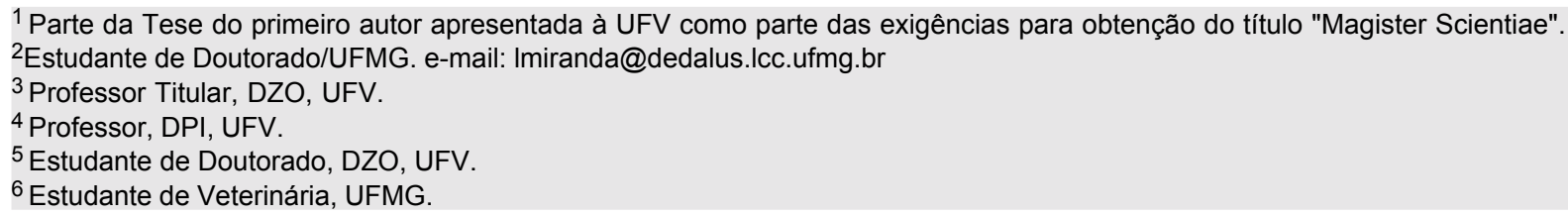


dispendido nos processos de mastigação e ruminação (BEAUCHEMIN e BUCHANAN-SMITH, 1989; DADO e ALLEN, 1995); neste aspecto, redução do tamanho da partícula, hidratação do alimento, exposição de nutrientes solúveis para fermentação e colonização microbiana são atividades básicas para os processos de digestão (VAN SOEST, 1994).

DESWYSEN et al. (1987) observaram que a duração do tempo de ruminação, expressa como proporção do consumo, é independente do peso vivo e negativamente relacionada ao consumo voluntário. No entanto, DESWYSEN et al. (1993), trabalhando com novilhas, observaram que o maior consumo de nutrientes está associado, primeiramente, ao menor tempo gasto ingerindo e ruminando.

O número de períodos ruminativos eleva-se com o aumento do conteúdo de fibra, refletindo a necessidade de processar a digesta ruminal, maximizando a eficiência digestiva (DADO e ALLEN, 1995). O tempo gasto com alimentação, ruminação e mastigação, por unidade de consumo de MS e FDN, é maior com adição de fibra na dieta; o aumento da atividade mastigatória pode proporcionar incremento da digestão ruminal e passagem.

A eficiência da ruminação é importante no controle da utilização de alimentos de baixa digestibilidade, pois o animal pode ruminar maiores quantidades de alimentos de baixa digestibilidade, durante as 8 ou 9 horas comuns de ruminação, proporcionando maior consumo de alimentos e melhor desempenho produtivo (WELCH, 1982). Porém, para DULPHY et al. (1980), a eficiência de ruminação e mastigação em gramas por hora pode ser reduzida para dietas de alta fibra, em virtude da maior dificuldade em reduzir o tamanho das partículas oriundas de materiais fibrosos.

O objetivo deste trabalho foi avaliar o comportamento ingestivo de novilhas leiteiras alimentadas com dietas à base de cana-de-açúcar suplementadas com fontes de nitrogênio não-protéico (NNP) e, ou, adição de probióticos.

\section{Material e Métodos}

Vinte e quatro novilhas mestiças Holandês-Zebu, com idade média de 15 meses e peso médio inicial de $247 \mathrm{~kg}$, foram mantidas em baias individuais com piso cimentado, bebedouros e área útil de $7 \mathrm{~m}^{2}$, sendo $1 / 3$ coberta com telhas de amianto, onde ficam os cochos de alimentação. O período de adaptação dos animais às dietas, às instalações e ao manejo experimental foi de 24 dias e o período experimental, de 84 dias. Os animais receberam 1,0 mL/50 kg PV de complexo vitamínico ADE, foram pesados, identificados por meio de brincos, vacinados contra febre aftosa e tratados contra endo e ectoparasitas.

Foram utilizadas seis dietas experimentais à base de cana-de-açúcar (Saccharum officinarum, L.), suplementadas com duas fontes de nitrogênio nãoprotéico (NNP) - uréia ou cama de frango, em substituição parcial da uréia - e três fontes de probióticos, sem probiótico, com levedura ou com microbiota ruminal, mais farelo de algodão, fosfato bicálcico, calcário e sal no concentrado. A cama de frango usada foi à base de capim napier. As dietas foram elaboradas conforme as exigências estabelecidas pelo NRC (1989), para ganho médio de $0,54 \mathrm{~kg}$.

Os teores de matéria seca (MS), matéria orgânica (MO), fibra em detergente neutro (FDN), proteína bruta $(\mathrm{PB})$, extrato etéreo (EE), cálcio, fósforo, potássio, sódio e magnésio da cana-de-açúcar, da cama de frango e dos concentrados utilizados na formulação das dietas, encontram-se na Tabela 1.

A relação volumoso:concentrado das dietas experimentais foi de 82:18 e 88:12 para as dietas suplementadas com uréia e cama de frango, em substituição parcial da uréia (tratamentos 1, 2, 3 e 4, 5, 6, respectivamente). Todas as dietas foram formuladas para serem isoprotéicas, com aproximadamente $12 \%$ de proteína bruta na matéria seca, sendo que a uréia dos tratamentos 1, 2 e 3 foi substituída, em parte, pela cama de frango nos tratamentos 4, 5 e 6 . A composição percentual e química dos ingredientes utilizados nas rações experimentais está apresentada na Tabela 2 .

As rações foram fornecidas à vontade, individualmente, uma vez ao dia, às $8 \mathrm{~h}$. A quantidade de ração fornecida diariamente foi reajustada de acordo com o consumo do dia anterior, de modo que houvesse sobra entre $10 \%$ do total fornecido, a fim de se garantir ingestão voluntária e grau de seleção uniforme de cada animal. As dietas experimentais fornecidas e as sobras dos cochos de cada novilha foram pesadas e amostradas diariamente.

Os animais foram submetidos à observação visual a cada 28 dias para avaliar o comportamento ingestivo das novilhas, durante dois dias consecutivos. No primeiro dia da observação, foi avaliado apenas um animal por tratamento, durante três períodos de duas horas ( 8 às 10 h; 14 às 16 h; e 18 às 20 h), medindo-se a média do número de mastigações merícicas por bolo ruminal e a média do tempo despendido de mastigação merícica por bolo ruminal, utilizando-se cronômetro 
digital. No segundo dia, o comportamento ingestivo de cada novilha foi determinado visualmente, a intervalos de 10 minutos, durante 24 horas, para determinar o tempo despendido em alimentação, ruminação e ócio.

O número de mastigações merícicas em 24 horas foi obtido mediante a multiplicação do tempo médio de ruminação, nas 24 horas do dia, pelo número de mastigações merícicas por minuto. O número médio de bolos em 24 horas foi obtido pela divisão do tempo médio de ruminação, nas 24 horas do dia, com o tempo médio de mastigações por bolo.

O delineamento experimental utilizado foi o inteiramente casualisado em esquema fatorial $2 \times 3$ (duas fontes de nitrogênio não-protéico $x$ três fontes de probiótico) com quatro repetições.

Os dados experimentais obtidos nos diversos tratamentos foram submetidos às análises de variância e as médias foram comparadas pelo teste de Tukey, a 1 e $5 \%$ de probabilidade, utilizando-se o pacote computacional SAEG (Sistema de Análise Estatística e Genética), UFV (1995), segundo o modelo estatístico:

em que

$$
\mathrm{Y}_{\mathrm{ijr}}=\mu+\mathrm{N}_{\mathrm{i}}+\mathrm{P}_{\mathrm{j}}+\mathrm{NP}_{\mathrm{ij}}+\mathrm{e}_{\mathrm{ijr}}
$$

$\mathrm{Y}_{\mathrm{ijr}}=$ observação referente ao animal $\mathrm{r}$ na fonte de nitrogênio i e do probiótico j;

$\mu=$ média geral;

$\mathrm{N}_{\mathrm{i}}=$ efeito da fonte de nitrogênio $\mathrm{i}(\mathrm{i}=1,2)$;

$\mathrm{P}_{\mathrm{j}}=$ efeito do probiótico $\mathrm{j}(\mathrm{j}=1,2,3)$;

$\mathrm{NP}_{\mathrm{ij}}=$ efeito da interação fonte de nitrogênio $\mathrm{x}$ probiótico; e

$\mathrm{e}_{\mathrm{ijr}}=$ erro aleatório associado a cada observação $(\mathrm{r}=1,2,3,4)$.

Para as variáveis \% consumo em 24 horas, \% ruminação em 24 horas, mastigações merícicas por dia, minuto, bolo, tempo de mastigações merícicas por bolo e bolos ruminais por dia, utilizou-se a estatística descritiva.

\section{Resultados e Discussão}

A interação entre as fontes de nitrogênio nãoprotéico e as fontes de probióticos não foi significativa para qualquer característica estudada.

Pode ser observado, na Figura 1, que a soma dos períodos 1 e 2 apresentou $84,96 \%$ do consumo total, e o elevado consumo durante o dia ocorreu, provavelmente, devido ao consumo de MS ter sido maior após o fornecimento de alimentação fresca (DADO e ALLEN, 1995). Observa-se, também, na Figura 2, que a ruminação ocorreu preferencialmente à noite, horário em que a temperatura foi mais amena, correspondendo a $66,76 \%$ da ruminação, nos períodos 3 e 4 . O padrão diário da atividade de ruminação apresentou valores elevados após 10 horas do fornecimento da alimentação diária, período 3 , mantendose em plena atividade durante as 12 horas subseqüentes, período 4 (Figura 2). POLLI et al. (1996) relataram que a distribuição da atividade de ruminação é bastante influenciada pela alimentação, já que a ruminação se processa logo após os períodos de alimentação, quando o animal está tranqüilo.

Os tempos despendidos consumindo, ruminando e

Tabela 1 - Composição químico-bromatológica (\% MS) da cana-de-açúcar, cama de frango e dos concentrados experimentais

Table 1 - Chemical composition (\% DM) of the sugar cane, broiler litter and experimental concentrates

\begin{tabular}{|c|c|c|c|c|}
\hline \multirow[t]{2}{*}{ Item } & \multirow[t]{2}{*}{$\begin{array}{l}\text { Cana-de-açúcar } \\
\text { Sugar cane }\end{array}$} & \multirow[t]{2}{*}{$\begin{array}{c}\text { Cama de frango } \\
\text { Broilerlitter }\end{array}$} & \multicolumn{2}{|c|}{$\begin{array}{c}\text { Concentrado } \\
\text { Concentrate }\end{array}$} \\
\hline & & & 1 & 2 \\
\hline Matéria seca & 25,50 & 81,29 & 84,67 & 86,49 \\
\hline Dry matter & & & & \\
\hline Matéria orgânica & 21,72 & 57,85 & 74,37 & 72,52 \\
\hline Organic matter & & & & \\
\hline Fibra detergente neutro & 60,35 & 62,95 & 53,18 & 48,78 \\
\hline Neutral detergent fiber & & & & \\
\hline Protéina bruta & 2,57 & 19,13 & 52,79 & 51,66 \\
\hline Crude protein & & & & \\
\hline Extrato etéreo & 0,49 & 0,30 & 0,41 & 0,58 \\
\hline Ether extract & & & & \\
\hline $\mathrm{Ca}$ & 0,73 & 3,08 & 1,84 & 1,84 \\
\hline $\mathrm{P}$ & 0,20 & 1,30 & 0,90 & 1,15 \\
\hline K & 2,31 & 2,47 & 1,36 & 1,30 \\
\hline $\mathrm{Na}$ & 0,06 & 0,54 & 0,51 & 0,82 \\
\hline Mn & 0,21 & 0,49 & 0,37 & 0,43 \\
\hline
\end{tabular}


Tabela 2 - Composição percentual dos alimentos e químico-bromatológica das dietas (\%MS)

Table 2 - Percentage and chemical composition of the ingredients of the diets (\% DM)

\begin{tabular}{|c|c|c|c|c|c|c|}
\hline \multirow[t]{2}{*}{$\begin{array}{l}\text { Ingrediente } \\
\text { Ingredient }\end{array}$} & \multicolumn{5}{|c|}{$\begin{array}{c}\text { Tratamento } \\
\text { Treatment }\end{array}$} & \multirow[b]{2}{*}{$6^{2}$} \\
\hline & 1 & $2^{1}$ & $3^{2}$ & 4 & $5^{1}$ & \\
\hline Cana-de-açúcar (Sugar cane) & 81,94 & 81,94 & 81,94 & 61,94 & 61,94 & 61,94 \\
\hline Cama de frango (Broiler litter) & - & - & - & 26,78 & 26,78 & 26,78 \\
\hline Farelo algodão (Cottonseed meal) & 14,99 & 14,99 & 14,99 & 9,55 & 9,55 & 9,55 \\
\hline Uréia (Urea) & 1,81 & 1,81 & 1,81 & 1,03 & 1,03 & 1,03 \\
\hline Fosfato bicálcico & 0,42 & 0,42 & 0,42 & 0,40 & 0,40 & 0,40 \\
\hline \multicolumn{7}{|l|}{ Dicalcium phosphate } \\
\hline Calcário (Limestone) & 0,61 & 0,61 & 0,61 & 0,59 & 0,59 & 0,59 \\
\hline Sal (Salt) & 0,23 & 0,23 & 0,23 & 0,24 & 0,24 & 0,24 \\
\hline Matéria seca (Dry matter) & 29,20 & 29,20 & 29,20 & 35,76 & 35,76 & 35,76 \\
\hline Protéina bruta & 11,70 & 11,70 & 11,70 & 12,78 & 12,78 & 12,78 \\
\hline \multicolumn{7}{|l|}{ Crude protein } \\
\hline Fibra detergente neutro & 59,05 & 59,05 & 59,05 & 59,68 & 59,68 & 59,68 \\
\hline \multicolumn{7}{|l|}{ Neutral detergent fiber } \\
\hline Matéria orgânica & 31,22 & 31,22 & 31,22 & 37,38 & 37,38 & 37,38 \\
\hline \multicolumn{7}{|l|}{ Organic matter } \\
\hline $\mathrm{Ca}$ & 0,93 & 0,93 & 0,93 & 1,48 & 1,48 & 1,48 \\
\hline $\mathrm{P}$ & 0,32 & 0,32 & 0,32 & 0,59 & 0,59 & 0,59 \\
\hline K & 2,13 & 2,13 & 2,13 & 2,23 & 2,23 & 2,23 \\
\hline $\mathrm{Na}$ & 0,14 & 0,14 & 0,14 & 0,26 & 0,26 & 0,26 \\
\hline Mn & 0,23 & 0,23 & 0,23 & 0,31 & 0,31 & 0,31 \\
\hline
\end{tabular}

$110 \mathrm{~g}$ de levedura/animal. $\mathrm{d}$ (10 $\mathrm{g}$ of yeast/animal. $\mathrm{d})$.

$210 \mathrm{~g}$ de microbiota ruminal/animal.d (10 g of ruminal microbiota/anima. $d$ ).

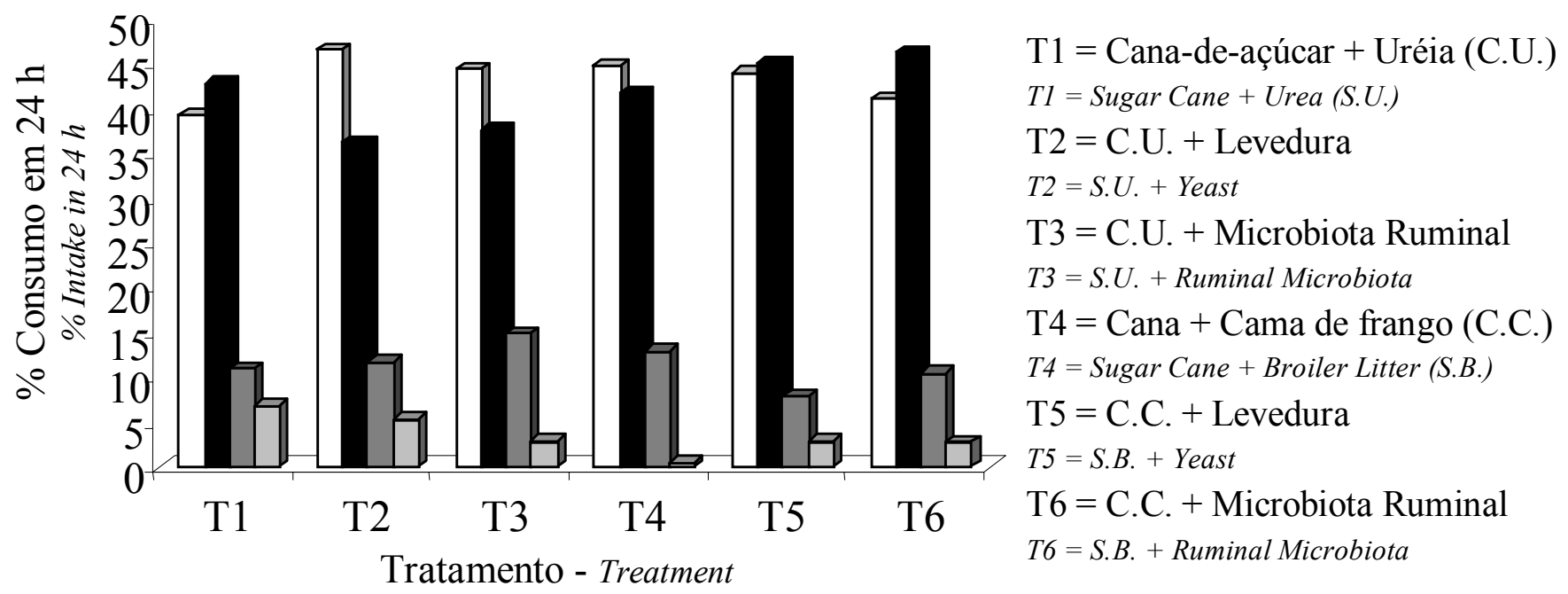

$\square \mathrm{P} 1$ 6-12h $\square \mathrm{P} 2$ 12-18h $\square \mathrm{P} 3$ 18-24h $\square \mathrm{P} 4$ 0-6h

Figura 1- Porcentagem de consumo, em quatro períodos (1, 2, 3, 4), nas 24 horas do dia.

Figure 1 - Percentage of the intake, in four periods (1,2,3,4), in the 24 hours of the day. 


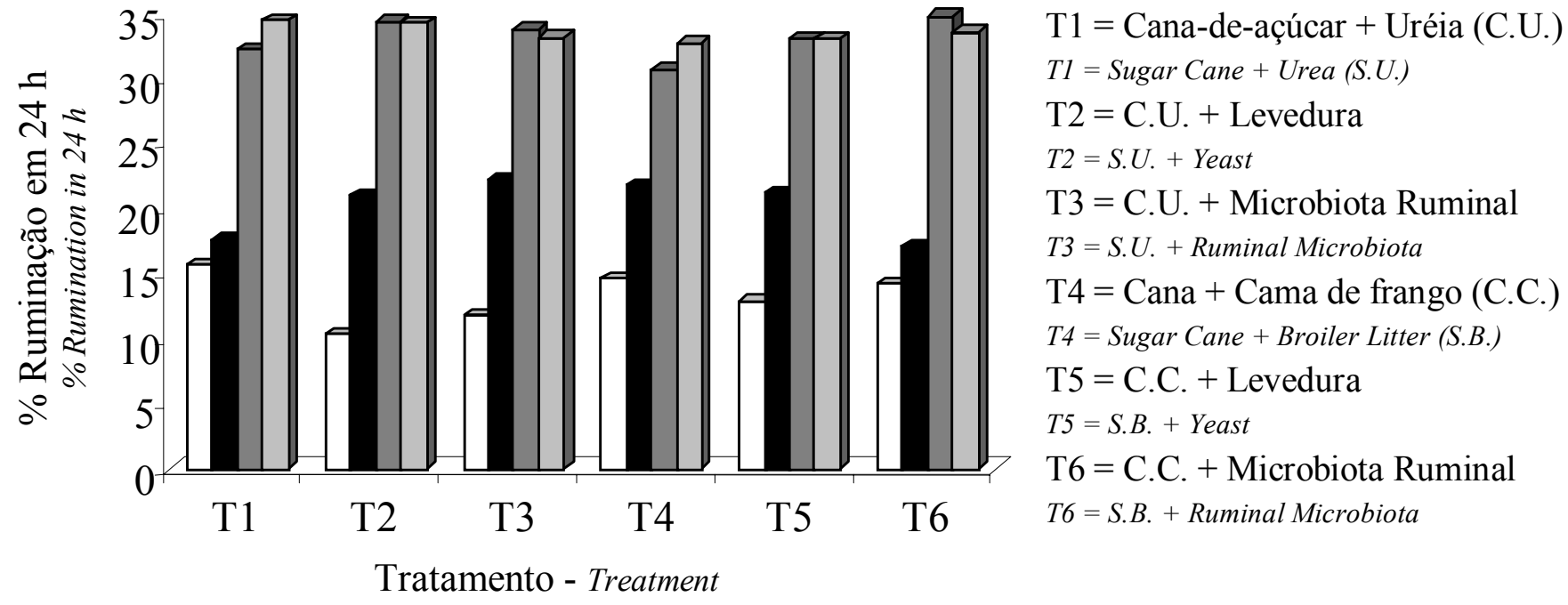

$\square$ P1 6-12h $\square$ P2 12-18h $\square$ P3 18-24h $\square$ P4 0-6h

Figura 2 - Porcentagem de ruminação, em quatro períodos (1, 2, 3, 4), nas 24 horas do dia.

Figure 2 - Percentage of the rumination, in four periods $(1,2,3,4)$, in the 24 hours of the day.

Tabela 3 - Média do consumo voluntário e das características do comportamento ingestivo e de ruminação de novilhas Table 3 - Average of voluntary intake and the ingestive and rumination behavior characteristics of heifers

\begin{tabular}{|c|c|c|c|c|c|c|}
\hline \multirow[t]{2}{*}{ Item } & \multicolumn{2}{|c|}{$\begin{array}{c}\text { Fonte de NNP } \\
\text { NPN source }\end{array}$} & \multicolumn{3}{|c|}{$\begin{array}{l}\text { Fonte de probiótico } \\
\text { Probiotic source }\end{array}$} & \multirow[b]{2}{*}{$\mathrm{CV}(\%)^{1}$} \\
\hline & $\begin{array}{l}\text { Uréia } \\
\text { Urea }\end{array}$ & $\begin{array}{c}\text { Cama de frango } \\
\text { Broiler litter }\end{array}$ & $\begin{array}{c}\text { Sem } \\
\text { Without }\end{array}$ & $\begin{array}{l}\text { Levedura } \\
\text { Yeast }\end{array}$ & $\begin{array}{l}\text { Microbiota ruminal } \\
\text { Ruminal microbiota }\end{array}$ & \\
\hline $\mathrm{N}^{0}$ médio de refeições/dia & 12,00 & 11,25 & 11,93 & 11,56 & 11,37 & 18,90 \\
\hline $\begin{array}{l}\text { N. of meals/day } \\
\text { Consumo }\end{array}$ & & & & & & \\
\hline $\begin{array}{l}\text { Intake } \\
\text { ko MS/d }\end{array}$ & & & & & & \\
\hline $\begin{array}{l}\mathrm{kg} M S / \mathrm{d} \\
\mathrm{kgFDN} / \mathrm{d}\end{array}$ & $\begin{array}{l}6,25^{\circ} \\
3,60^{b}\end{array}$ & $\begin{array}{l}7,31^{\mathrm{a} * *} \\
4,28^{\mathrm{a} * *}\end{array}$ & $\begin{array}{l}6,33 \\
3,68\end{array}$ & $\begin{array}{l}7,15 \\
4,17\end{array}$ & $\begin{array}{l}6,86 \\
3,97\end{array}$ & $\begin{array}{l}11,45 \\
12,74\end{array}$ \\
\hline $\mathrm{min} / \mathrm{dia}$ & 318,6 & 324 & 303,6 & 325,8 & 334,2 & 14,47 \\
\hline $\mathrm{min} / \mathrm{kg} \mathrm{MS}$ & 51,97 & 44,91 & 50,58 & 42,38 & 52,36 & 20,22 \\
\hline $\mathrm{min} / \mathrm{kgFDN}$ & 90,65 & 76,93 & 87,41 & 72,87 & 91,08 & 21,07 \\
\hline kg MS/refeição & $0,53^{b}$ & $0,68^{a} *$ & 0,60 & 0,63 & 0,58 & 25,99 \\
\hline Duração das refeições & 27,14 & 30,27 & 29,05 & 26,35 & 30,72 & 22,07 \\
\hline Duration of meals & & & & & & \\
\hline $\begin{array}{l}\mathrm{N}^{\mathrm{o}} \text { períodos ruminação/dia } \\
N \text {. rumination periods/day }\end{array}$ & 15,04 & 14,97 & 15,56 & 14,18 & 15,25 & 11,49 \\
\hline Duração período ruminação & 41,73 & 38,86 & 41,83 & 40,03 & 39,02 & 15,24 \\
\hline $\begin{array}{l}\text { Duration rumination period } \\
\text { Tempo ruminação }\end{array}$ & & & & & & \\
\hline Ruminating time & & & & & & \\
\hline $\mathrm{min} / \mathrm{dia}$ & 589,2 & 571,2 & 581,4 & 578,4 & 580,8 & 6,81 \\
\hline $\mathrm{min} / \mathrm{kg} \mathrm{MS}$ & $96,29^{a}$ & $79,07^{\mathrm{b} * *}$ & 90,24 & 78,80 & 94,01 & 16,40 \\
\hline $\mathrm{min} / \mathrm{kgFDN}$ & $168,02^{\mathrm{a}}$ & $135,36^{\mathrm{b} * *}$ & 155,78 & 135,56 & 163,73 & 17,56 \\
\hline Tempo total de mastigação & & & & & & \\
\hline Total mastication time & & & & & & \\
\hline $\min /$ dia & 893,25 & 895,05 & 919,42 & 867,45 & 895,57 & 9,07 \\
\hline $\mathrm{min} / \mathrm{kg} \mathrm{MS}$ & $145,27^{\mathrm{a}}$ & $123,97^{b} *$ & 140,81 & 121,19 & 141,86 & 16,09 \\
\hline $\mathrm{min} / \mathrm{kgFDN}$ & $253,33^{\mathrm{a}}$ & $212,29^{b} *$ & 243,21 & 208,45 & 246,77 & 17,05 \\
\hline
\end{tabular}

Médias, na linha, seguidas de letras diferentes, para cada fonte, são diferentes ( $\left.{ }^{*} \mathrm{P}<0,05\right),\left({ }^{* *} \mathrm{P}<0,01\right)$ pelo teste Tukey.

Means, within a row, followed by different letters, for each source, are different $\left({ }^{*} P<.05\right),\left({ }^{* *} P<.01\right)$ by Tukey test.

$\mathrm{kg} \mathrm{MS} / \mathrm{d}$ (kg DM/d), kg FDN/d (kg NDF/d), min./d, min./kg MS (min./kg DM), min./kg FDN (min./kg NDF) e kg MS/refeição (kg DM/meal). 
mastigando (mastigação de alimentação e ruminação) estão apresentados na Tabela 3. Não houve diferença em relação ao tempo despendido em alimentação, ruminação e mastigação total, em min/dia, das novilhas alimentadas com diferentes fontes de NNP e probióticos, provavelmente, porque as dietas apresentaram teores semelhantes de FDN e os tempos gastos com alimentação, ruminação e mastigação foram influenciados pelo conteúdo de FDN dietética (BEAUCHEMIN e BUCHANAN-SMITH, 1989; McLeod, 1986, citado por THIAGO et al., 1992). Entretanto, o tempo gasto com alimentação e ruminação foi elevado, devido ao alto teor de FDN das dietas experimentais, pois o tempo despendido em ruminação é proporcional ao teor de FDN dos volumosos (VAN SOEST, 1994).

Os resultados obtidos para o tempo médio de ruminação em $\mathrm{min} / \mathrm{kg}$ de $\mathrm{MS}$ e FDN, em relação às fontes de NNP, foram maiores $(\mathrm{P}<0,01)$ para os animais alimentados com uréia. Apesar de o tempo médio de ingestão e mastigação, em $\mathrm{min} / \mathrm{kg}$, de MS e FDN não ter apresentado diferença entre as fonte de NNP, as dietas suplementadas com uréia apresentaram valores numericamente maiores (Tabela 3). Como o maior consumo médio diário de MS está associado, primeiramente, com menor tempo gasto ingerindo e ruminando diariamente (DESWYSEN et al., 1993), constata-se que o menor consumo de MS e FDN das dietas suplementadas com uréia é atribuído, principalmente, ao maior tempo gasto ruminando.

O número de refeições e períodos de ruminação por dia não apresentou diferenças em relação às fontes de NNP e às fontes de probióticos. Observou-se média de
11,62 refeições/dia, com duração média de 28,70 minutos e média de 15 períodos ruminativos/dia, com duração média de 40,29 minutos. Contudo, como não se observou diferença no número de refeições diárias com relação à fonte de NNP e de probiótico, as diferenças encontradas no consumo de MS por refeição, para as dietas com uréia e cama de frango, respectivamente, segundo DADO e ALLEN (1995), são atribuídas às diferenças de consumo de MS diário, que foi maior para as dietas contendo cama de frango, pois estas apresentaram maior proporção de MS (Tabela 3).

Os animais alimentados com cama de frango apresentaram melhor $(\mathrm{P}<0,01)$ eficiência de ruminação de MS e FDN, pois gastaram menor tempo de ruminação e tempo numericamente menor com alimentação, que, provavelmente, ocorreu em virtude do maior teor de matéria seca das dietas suplementadas com cama de frango (BEAUCHEMIN e BUCHANAN-SMITH, 1989; DESWYSEN et al., 1993) (Tabela 4). Uma vez que redução na eficiência de ruminação não pode ser compensada pelo prolongamento da atividade de ruminação, a eficácia de ruminação é importante no controle da utilização de volumosos e pode restringir a utilização de alimentos de baixa qualidade, comprometendo a produção animal (WELCH, 1982).

Observa-se, nas Figuras 3 (a, b, c, d), que os animais alimentados com uréia (tratamentos 1, 2 e 3 ) mostraram tendência de maior número de mastigações merícicas por dia, minuto, bolo e de forma mais lenta. Como o tempo gasto com alimentação é um dos fatores limitantes do consumo de forragem, em função do número de movimentos mastigatórios (ALBRIGHT, 1993), essas dietas apresentaram me-

Tabela 4 - Média da eficiência de alimentação e ruminação da MS e FDN Table 4 - Average of feeding and rumination eficiency of the DM and NDF

\begin{tabular}{|c|c|c|c|c|c|c|}
\hline \multirow[t]{2}{*}{ Item } & \multicolumn{2}{|c|}{$\begin{array}{l}\text { Fonte de NNP } \\
N P N \text { source }\end{array}$} & \multicolumn{3}{|c|}{$\begin{array}{l}\text { Fonte de probiótico } \\
\text { Probiotic source }\end{array}$} & \multirow[b]{2}{*}{$\mathrm{CV}(\%)^{1}$} \\
\hline & $\begin{array}{l}\text { Uréia } \\
\text { Urea }\end{array}$ & $\begin{array}{c}\text { Cama de frango } \\
\text { Broiler litter }\end{array}$ & $\begin{array}{l}\text { Sem } \\
\text { Without }\end{array}$ & $\begin{array}{c}\text { Levedura } \\
\text { Yeast }\end{array}$ & $\begin{array}{l}\text { Microbiota ruminal } \\
\text { Ruminal microbiota }\end{array}$ & \\
\hline Eficiência de & 1203,81 & 1383,56 & 1275,54 & 1341,84 & 1263,67 & 20,20 \\
\hline $\begin{array}{l}\text { Feeding eficiency } g \mathrm{DM} / \mathrm{h} \\
\text { Eficiência de } \\
\text { alimentação g FDN/h } \\
\text { Feeding eficiency } g \mathrm{NDF} / \mathrm{h}\end{array}$ & 691,83 & 812,24 & 742,68 & 782,69 & 730,74 & 21,67 \\
\hline $\begin{array}{l}\text { Eficiência de } \\
\text { ruminação g MS/h }\end{array}$ & $641,03^{b}$ & $771,76^{\mathrm{a} * *}$ & 660,13 & 745,34 & 713,71 & 15,19 \\
\hline $\begin{array}{l}\text { Rumination eficiencyg } \mathrm{DM} / \mathrm{h} \\
\text { Eficiência de } \\
\text { ruminação } \mathrm{g} \text { FDN } / \mathrm{h} \\
\text { Rumination eficiency } \mathrm{g} N \mathrm{~N} / \mathrm{h}\end{array}$ & $368,51^{\mathrm{b}}$ & $452,40^{\mathrm{a} * *}$ & 383,69 & 434,82 & 412,86 & 16,32 \\
\hline
\end{tabular}


nor consumo de nutrientes.

FISCHER et al. (1997) relataram que os animais que consomem mais alimento apresentaram menor número de bolos ruminais e menor tempo de mastigação por bolo; entretanto, nas dietas suplementadas com cama de frango, observaram-se maior consumo, menor número de bolos ruminais por dia (Figura $3 \mathrm{e}$ ) e tendência de maior tempo de mastigação por bolo, Figura 3d (tratamentos 4, 5 e 6). Isso ocorreu em virtude da composição da dieta com cama de frango.
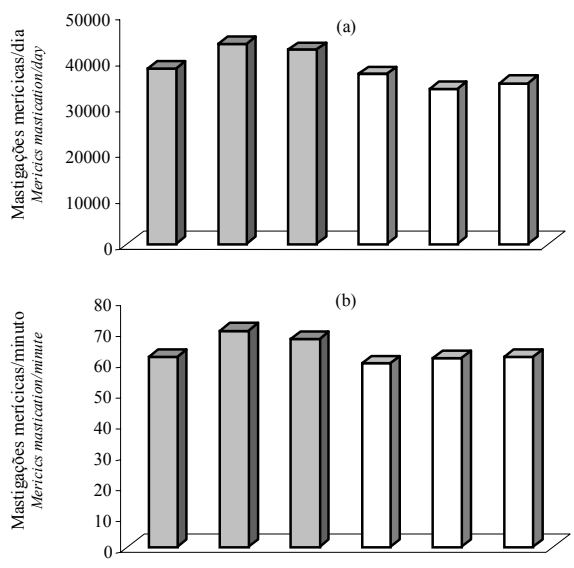

(c)
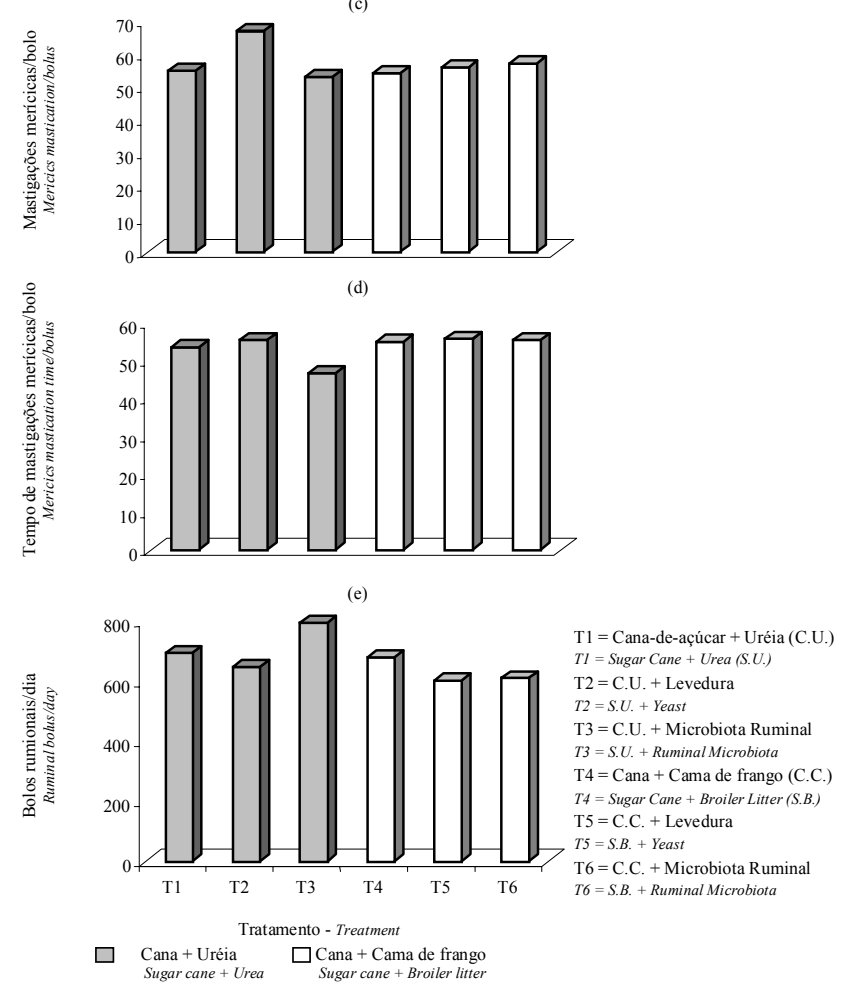

Figura 3 - Número de mastigações merícicas por dia (a), minuto (b), bolo (c), tempo de mastigações merícicas por bolo (d) e número de bolos ruminais por dia (e).

Figure 3 - Number of mericics mastication per day (a), minute (b), bolus (c), mericics mastication time per bolus (d) and number ruminal bolus per day (e).

\section{Conclusões}

O comportamento ingestivo das novilhas não foi influenciado pelas fontes de nitrogênio não-protéico e pela adição de probiótico.

\section{Referências Bibliográficas}

ALBRIGHT, J.L. 1993. Feeding behavior of dairy cattle. J. Dairy Sci., 76(2):485-498.

BEAUCHEMIN, K.A., BUCHANAN-SMITH, J.G. 1989. Effects of neutral detergente fiber concentration and suplementary long hay on chewing activities and milk production of dairy cows. J. Dairy Sci., 72(9):2288-2300.

DADO, R.G., ALLEN, M.S. 1995. Intake limitation, feeding behavior, and rumen function of cows challenged with rumen fill from dietary fiber or inert bulk. J. Dairy Sci., 78(1):118-133.

DADO, R.G., ALLEN, M.S. 1994. Variation in and relationships among feeding, chewing, and drinking variables for lacting dairy cows. J. Dairy Sci., 77(1):132-144.

DESWYSEN, A.G., DUTILlEUL, P., GODFRIN, J.P. et al. 1993. Nycterohemeral eating and ruminating pattern in heiffers fed grass or corn silagem: analysis by finite fourier transform. J. Anim. Sci., 71(10): 2739-2747.

DESWYSEN, A.G., ELLIS, W.C., POND, K.R. 1987. Interrelationships among voluntary intake, eating and ruminating behavior and ruminal motility of heifers fed corn silage. J. Anim. Sci., 64(3):835-841.

DULPHY, J.P., REMOND, B., THERIEZ, M. 1980. Ingestive behavior and related activities in ruminants. In: RUCKEBUSH, Y., THIVEND, P.(Eds). Digestive physiology and metabolism in ruminants. Lancaster: MTP. p.103-122.

FISHER, V., DESWYSEN, A.G., DÈSPRES, L. et al. 1997. Comportamento ingestivo de ovinos recebendo dieta à base de feno durante um período de seis meses. R. Soc. Bras. Zootec., 26(5):1032-1038.

NATIONAL RESEARCH COUNCIL - NRC. 1989. Nutrients requeriments of dairy cattle. 6 ed. Washington D.C., National Academy of Sciences. $158 \mathrm{p}$.

POLLI, V.A., RESTLE, J., SENNA, D.B. et al. 1996 . Aspectos relativos à ruminação de bovinos e bubalinos em regime de confinamento. R. Soc. Bras. Zootec., 25(5):987-993.

THIAGO, L.R.L., GILL, M., SISSONS, J.W. 1992. Studies of conserving grass herbage and frequency of feeding in cattle. Br. J. Nutr., 67(3):339-336.

UNIVERSIDADE FEDERAL DE VIÇOSA (UFV). S.A.E.G. 1995. (Sistema de Análises Estatísticas e Genéticas). Viçosa, MG (Versão 5.0).

VAN SOET, P.J. 1994. Nutritional ecology of the ruminant. 2 ed. Ithaca: Cornell. 476p.

WELCH, J.G. 1982. Rumination, particle size and passage from the rumen. J. Anim. Sci., 54(4):885-895. 